\title{
Age estimation of Antarctic minke whales Balaenoptera bonaerensis based on aspartic acid racemization technique
}

\author{
Genta Yasunaga ${ }^{1}\left({ }^{\circ} \cdot\right.$ Luis A. Pastene $^{1} \cdot$ Takeharu Bando $^{1} \cdot$ Takashi Hakamada $^{1}$. \\ Yoshihiro Fujise $^{1}$
}

Received: 7 April 2017 / Accepted: 30 July 2017 / Published online: 16 August 2017

(C) The Author(s) 2017. This article is an open access publication

\begin{abstract}
Counting of the growth layers in the earplugs is the most accepted technique for determining chronological age of Antarctic minke whales; however, unreadable growth layers form in some individuals, especially in young animals. In this study, aspartic acid racemization (AAR) technique was developed for estimating ages in this species with the aim of complementing the age estimated using earplugs. To validate the technique and to determine the specific coefficients for age estimation, the ratio of $\mathrm{D}$ and L-enantiomers of aspartic acid (Asp $D / L)$ in lens of 18 whales and 20 fetuses were analyzed and compared with earplug-based age estimates. The equation for age estimation by AAR in this species was as follows: $\log _{\mathrm{e}}\{[1+$ (Asp $\left.\left.D / L)_{\text {act }}\right] /\left[1-(\operatorname{Asp} D / L)_{\text {act }}\right]\right\}=2.30 \times 10^{-3} \times$ earplug age (year) $+0.0201\left(p<0.001, r^{2}=0.918\right)$. There is a strong correlation between the age estimates by AAR and earplugs. This study was successful in developing the AAR technique for the Antarctic minke whale, and the application of this technique can complement the age estimation of this species based on earplug readings, especially for young animals with unreadable earplugs.
\end{abstract}

Genta Yasunaga

yasunaga@cetacean.jp

Luis A. Pastene

pastene@ cetacean.jp

Takeharu Bando

bando@ cetacean.jp

Takashi Hakamada

hakamada@cetacean.jp

Yoshihiro Fujise

fujise@ cetacean.jp

1 Institute of Cetacean Research, 4-5 Toyomi-cho, Chuo-ku, Tokyo 104-0055, Japan
Keywords Antarctic minke whale $\cdot$ Lens $\cdot$ Age estimation $\cdot$ Racemization $\cdot$ Aspartic acid

\section{Introduction}

Age is one of the most important life history parameters for assessment and management of marine living resources. In baleen whales, age has been estimated using a variety of methods such as eye lenses [1], baleen plates [2, 3], earplugs [4, 5] and tympanic bulla [6]. Counting of the growth layers deposited in the earplugs is the most accepted technique for determining chronological age of baleen whales [7]. Earplug-based age estimation has the advantages that it is time- and cost-efficient, and the technique can be used on available historical samples; however, unreadable growth layers form in some individuals [8] and species [9] of baleen whales. The aspartic acid racemization (AAR) technique for estimating ages is based on temporal changes of the ratio of $\mathrm{D}$ and L-enantiomers of aspartic acid $(\operatorname{Asp} D / L)$ in mammals $[10,11]$. The technique is based on the principle that D-aspartic acid accumulates logarithmically with age, and the crystalline in the core of the lens has been conserved chemically since it is formed at the fetus stage and is metabolically inactive for all of the animal's life [10]. AAR is useful for age estimation in long-lived mammals because the rate of racemization process depends only on the age and temperature $[10,11]$.

Previous studies have reported on the application of the AAR technique to baleen whale species. Nerini [12] revealed a clear relationship between earplug-based ages and Asp $D / L$ in fin whales. George et al. [9] applied AAR to estimate ages of bowhead whales, a species having unreadable earplugs. In that study, the rate of the racemization reaction of aspartic acid in eye lens $\left(k_{\mathrm{Asp}}\right)$ was extrapolated from human [10] 
and fin whale [12], and the Asp $D / L$ in eye lens at birth, $(D / L)_{0}$, was estimated from an average of eight bowhead whales aged 0 to about 2-years-old. Olsen and Sunde [13] applied AAR to estimate ages of common minke whales from the North Atlantic, and $k_{\text {Asp }}$ was calculated from data in George et al. [9] as a function of body temperature. $(D / L)_{0}$ was also extrapolated from that study [9]. Rosa et al. [14] applied AAR for estimating the ages in bowhead whales. They calculated $k_{\mathrm{Asp}}$ from ovarian corpora counts, and estimated $(D / L)_{0}$ from corpora age assuming that the female age at sexual maturity was 20-years-old.

The studies mentioned above, excepting that of Nerini [12], were based on extrapolated $k_{\mathrm{Asp}}$ data from other studies as no age data were available for validation or comparison purposes. In addition, $(D / L)_{0}$ was also extrapolated or assumed in those studies because no sufficient fetus or neonate samples were available for such estimation. The earplug-based technique works well in the case of Antarctic minke whales Balaenoptera bonaerensis except with young animals where growth layers are difficult to read [8].

The aim of this study was to develop the AAR technique for age estimation in the Antarctic minke whale. Age information from the AAR will complement the age estimation based on earplug readings, especially for the more difficult young animals. There is plenty of biological information collected from Antarctic minke whales that makes assumptions and extrapolations of key parameters unnecessary. For example $k_{\mathrm{Asp}}$ and $(D / L)_{0}$ can be determined by direct comparison with earplug-based estimated ages, and $(D / L)_{0}$ can be estimated using available fetal samples from the Antarctic minke whales. Furthermore, the precision of the age estimation by the AAR ages of whales can be estimated.

\section{Materials and methods}

\section{Biological sampling}

Antarctic minke whales were sampled in the Antarctic sector corresponding to the Indo region, which correspond to the International Whaling Commission (IWC)'s management Area IV $\left(70^{\circ}-130^{\circ} \mathrm{E}\right)$, south of $62^{\circ} \mathrm{S}$ (Fig. 1). Whales were sampled during the austral summer seasons 2005/2006 and 2007/2008 in JARPAII (Japanese Whale Research Program under Special Permit in the Antarctic-Phase II). Whales were sampled through a pre-determined zigzag track-line designed to cover the whole research area (Area IV). In order to obtain biological samples representing the whole population in the research area, a random sampling method under the line transect sighting survey was adopted (see details in [15]). Whales were killed using penthrite grenade harpoon. The lethal sampling of whales under the JARPAII program was based on a permit issued by the Government of Japan in accordance with the provisions of Article VIII of the International Convention for the Regulation of Whaling (ICRW).

In the field, scientists collected the left eye ball from 20 fetuses and lens samples from 18 female Antarctic minke whales. The samples were stored in polyethylene bags at $-80{ }^{\circ} \mathrm{C}$ until analysis.

\section{Biological information}

Table 1 shows information on sex, body weight, age, and measured and actual $D / L$ ratios of aspartic acid, based on 20 fetus samples. The weight of the fetuses was measured

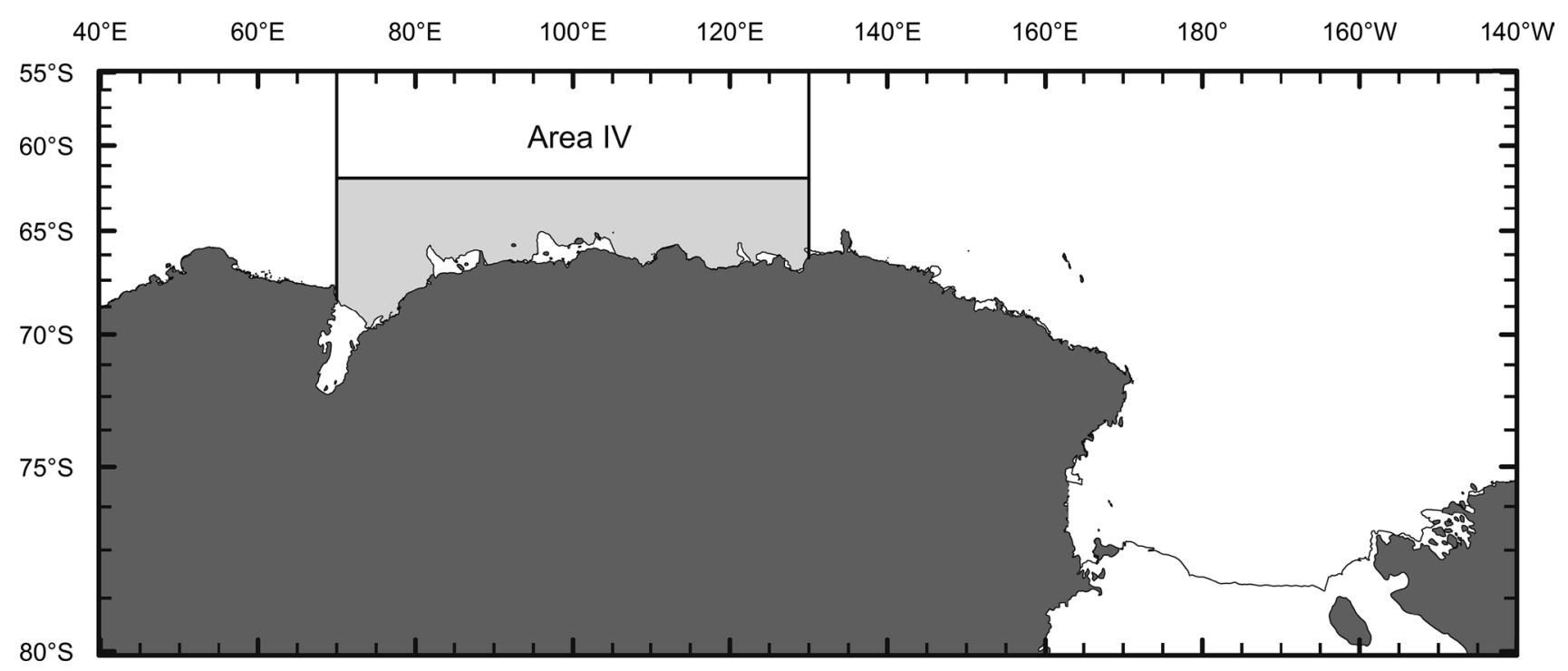

Fig. 1 Research area in the 2005/2006 and 2007/2008 austral summer seasons 
Table 1 Biological information and the measured and actual $D / L$ ratios of aspartic acid of 20 fetuses of Antarctic minke whale

\begin{tabular}{llllll}
\hline Sample no. & Sex & Body weight $(\mathrm{kg})$ & Fetus age & $(D / L)_{\text {meas }}($ days $)$ & $(D / L)_{\text {act }}$ \\
\hline 07/08-AM363F & M & 49.4 & 227 & 0.0279 & 0.0117 \\
07/08-AM380F & M & 19.0 & 185 & 0.0283 & 0.0122 \\
07/08-AM383F & F & 64.1 & 241 & 0.0289 & 0.0130 \\
07/08-AM392F & M & 29.9 & 203 & 0.0277 & 0.0116 \\
07/08-AM393F & M & 19.2 & 186 & 0.0276 & 0.0114 \\
07/08-AM461F & M & 59.3 & 236 & 0.0287 & 0.0127 \\
07/08-AM474F & M & 35.8 & 211 & 0.0276 & 0.0114 \\
07/08-AM475F & F & 63.2 & 240 & 0.0280 & 0.0119 \\
07/08-AM481F & M & 21.9 & 191 & 0.0280 & 0.0119 \\
07/08-AM502F & M & 78.5 & 252 & 0.0287 & 0.0127 \\
07/08-AM504F & M & 14.0 & 174 & 0.0276 & 0.0114 \\
07/08-AM516F & F & 22.1 & 191 & 0.0285 & 0.0124 \\
07/08-AM523F & M & 108.0 & 272 & 0.0284 & 0.0123 \\
07/08-AM527F & M & 34.6 & 210 & 0.0286 & 0.0126 \\
07/08-AM531F & M & 100.0 & 267 & 0.0284 & 0.0123 \\
07/08-AM533F & F & 194.5 & 315 & 0.0297 & 0.0138 \\
07/08-AM542F & F & 98.0 & 266 & 0.0288 & 0.0127 \\
07/08-AM550F & F & 58.8 & 236 & 0.0287 & 0.0127 \\
05/06-AM588F & M & 49.0 & 226 & 0.0284 & 0.0123 \\
05/06-AM820F & F & 53.6 & 231 & 0.0271 & 0.0108 \\
\hline
\end{tabular}

onboard the research-base vessel, using a marine scale (M1100 PL2260, Marel Co. Ltd.) equipped with motion compensation devices (precision $<1 \%$ ). To convert the fetal weight ( $W: \mathrm{g})$ into fetal age ( $t$ : day), the following equation was used [16]:

$t=W^{1 / 3} / 0.24+74$.

Table 2 shows information on sex, age (year) estimated from earplugs $[4,5]$ and measured and actual $D / L$ ratios of aspartic acid based on 18 female samples.

\section{Preparation of samples}

Lenses were rinsed first with phosphate-buffered saline. Then their outermost layers were removed with mucus, and the cores were dissected out using a surgical knife.

Sample preparation and the high performance liquid chromatography analysis (HPLC) were done mainly by following the procedures by Fujii et al. [17]. Then, $10 \mathrm{mg}$ of core samples were homogenized with $1 \mathrm{ml}$ of tris-buffer (200 mM Tris, $150 \mathrm{mM} \mathrm{NaCl}, \mathrm{pH} 8.0$ ) using an ultrasonic homogenizer. The homogenate was centrifuged at $15,000 \times g$ for $15 \mathrm{~min}$ at $4{ }^{\circ} \mathrm{C}$, and $100 \mu \mathrm{l}$ of the supernatant was then desalted with acetone and air-dried. They were hydrolyzed in the gas-phase $\mathrm{HCl}$ (6N-HCl) for $7 \mathrm{~h}$ at $108{ }^{\circ} \mathrm{C}$ (Pico Tag Work Stations, Waters, Tokyo). The hydrolysates were evaporated under reduced pressure.
Table 2 Biological information and the measured and actual $D / L$ ratios of aspartic acid of 18 female Antarctic minke whales

\begin{tabular}{lrlll}
\hline Sample no. & Earplug age & $(D / L)_{\text {meas }}$ & $(D / L)_{\text {act }}$ & $\begin{array}{l}L^{L o g} \\
{[(1+D / L) /} \\
(1-D / L)]\end{array}$ \\
\hline 05/06-AM348 & 14 & 0.0371 & 0.0223 & 0.0446 \\
05/06-AM349 & 21 & 0.0463 & 0.0328 & 0.0656 \\
05/06-AM352 & 9 & 0.0370 & 0.0222 & 0.0444 \\
05/06-AM361 & 26 & 0.0555 & 0.0432 & 0.0865 \\
05/06-AM372 & 40 & 0.0552 & 0.0430 & 0.0860 \\
05/06-AM382 & 7 & 0.0328 & 0.0173 & 0.0347 \\
05/06-AM386 & 8 & 0.0342 & 0.0190 & 0.0380 \\
05/06-AM398 & 7 & 0.0320 & 0.0164 & 0.0329 \\
05/06-AM488 & 4 & 0.0295 & 0.0136 & 0.0272 \\
05/06-AM498 & 4 & 0.0308 & 0.0151 & 0.0302 \\
05/06-AM517 & 3 & 0.0269 & 0.0106 & 0.0212 \\
05/06-AM539 & 1 & 0.0285 & 0.0124 & 0.0249 \\
05/06-AM565 & 2 & 0.0328 & 0.0174 & 0.0348 \\
05/06-AM592 & 4 & 0.0324 & 0.0169 & 0.0337 \\
05/06-AM603 & 6 & 0.0328 & 0.0173 & 0.0346 \\
05/06-AM615 & 7 & 0.0322 & 0.0167 & 0.0333 \\
05/06-AM630 & 5 & 0.0309 & 0.0152 & 0.0305 \\
05/06-AM634 & 3 & 0.0286 & 0.0125 & 0.0250 \\
\hline
\end{tabular}

\section{Laboratory and quantitative procedures}

The Asp $D / L$ was determined using HPCL (Alliance ${ }^{\circledR}$ HPLC systems e2696, Waters) with a Nova-Pak ODS column 
(3.9 $\mathrm{mm} \times 300 \mathrm{~mm}$, Waters) using fluorescence detection (344 nm excitation wavelength and $443 \mathrm{~nm}$ emission wave length). Elution was carried out with an isocratic adsorption of $3 \%$ acetonitrile $+3 \%$ tetrahydrofuran/0.1 M acetate buffer $\mathrm{pH} 6.0$ at a flow rate of $0.8 \mathrm{ml} / \mathrm{min}$ and column temperature of $23{ }^{\circ} \mathrm{C}$. Then, $70 \mu \mathrm{l}$ of borate buffer $(0.1 \mathrm{M}, \mathrm{pH} 10.4), 5 \mu \mathrm{l}$ of $n$-tert-butyloxycarbonyl-L-cysteine and $5 \mu \mathrm{l}$ of $o$-phthalaldehyde were successively added to $5 \mu \mathrm{l}$ of the hydrolysate dissolved in $0.1 \mathrm{~N}-\mathrm{HCl}$. The measured Asp $D / L,(D / L)_{\text {meas }}$, was calibrated against real ratios in the standard solutions, and the calibrated ratio was represented as $(D / L)_{\text {calib. Preci- }}$ sion, linearity and accuracy were assessed using the standard solutions of aspartic acid (Asp D/L 0.010, 0.020, 0.030, $0.040,0.050,0.060,0.070$ and 0.075$)$.

\section{Correction for hydrolysis effect}

For validation of the hydrolysis effect, the purified fetus samples, 07/08-AM533F, were hydrolyzed in the gas-phase $6 \mathrm{~N}-\mathrm{HCl}$ for $7,14,21,28$ and $35 \mathrm{~h}$ at $108{ }^{\circ} \mathrm{C}$, respectively.

\section{Method of age estimation and statistical procedure}

The formula of Bada et al. [10] was used:

$$
\begin{aligned}
2 k_{\mathrm{Asp}} t= & \log _{\mathrm{e}}[(1+D / L) /(1-D / L)] \\
& -\operatorname{Ln}\left\{\left[1+(\mathrm{D} / \mathrm{L})_{0}\right] /\left[1-(\mathrm{D} / \mathrm{L})_{0}\right]\right\},
\end{aligned}
$$

where $t$ (year) is the age of the whale. Standard error (SE) and $95 \%$ confidence interval for the AAR-based age estimates were calculated following the procedures of Rosa et al. [14]. First, 2,000 pairs of $(D / L)_{0}$ and $k_{\text {Asp }}$ were generated from a bivariate normal distribution with mean values of the actual estimates and covariance matrix derived from the regression. Second, 2,000 replicates of $(D / L)_{\text {act }}$ for each whale were generated from normal distribution with mean whales' $(D / L)_{\text {act }}$ and their standard deviations (SDs). Then 2,000 replicate values of age calculated from the replicate pairs of $(D / L)_{0}$ and $k_{\text {Asp }}$ provided averages and the SDs of age.

The correlations between $(D / L)_{\text {meas }}$ and the real ratios in the standard solutions, $(D / L)_{\text {meas }}$ and hydrolysis time, and $(D / L)_{\text {act }}$ and fetal age in fetuses were assessed by the Pearson correlation test. Differences of $(D / L)_{\text {meas }}$ analyses among measurement days were assessed by one-way ANOVA. The $k_{\text {Asp }}$ and the $(D / L)_{0}$ were assessed by simple linear regression analysis. The SEs of AAR ages were performed by bootstrap simulation. A $p$ value of 0.05 was the significant level of the test. Pearson correlation test, one-way ANOVA and simple linear regression analysis were executed by PASW Statics 17.0 for Windows (SPSS Co. Ltd.). Bootstrap simulation was executed by $\mathrm{R}$ environment version 3.2.2 [18].

\section{Results}

\section{Linearity, calibration and precision of the Asp D/L analysis}

To evaluate linearity of the Asp $D / L$ analysis, $D / L$ mixtures of aspartic acid $(0.010,0.020,0.030,0.040,0.050,0.060$ and 0.070 ) were measured three times each.

Table 3 shows the relationship between measurements and real ratios of Asp $D / L$ of the standard solutions. The $(D / L)_{\text {meas }}$ correlated with real Asp $D / L$ (Pearson correlation test; $\left.p<0.05, r^{2}=1.000\right)$. The data yielded the following linear regression equation:

$(D / L)_{\text {calib }}=1.142 \times(D / L)_{\text {meas }}+0.00119 \quad\left(p<0.05, r^{2}=1.000\right)$.

To evaluate the precision of $(D / L)_{\text {calibs }}, D / L$ mixtures of aspartic acid $(0.025,0.050$ and 0.075$)$ were measured ten, ten and nine times, respectively. Their precision of $(D / L)_{\text {calibs }}$ were averaged $0.0143(\mathrm{SD}=0.00022, \mathrm{CV}=0.0156), 0.0331$ $(\mathrm{SD}=0.00025, \mathrm{CV}=0.00759)$ and $0.0526(\mathrm{SD}=0.00055$, $\mathrm{CV}=0.0105)$, respectively. These results showed a high precision of $(D / L)_{\text {calib }}$ analyses in this study.

\section{Correction for hydrolysis effect}

The $(D / L)_{\text {calibs }}$ in lens of the fetus hydrolyzed for $7,14,21$, 28 and $35 \mathrm{~h}$ at $108{ }^{\circ} \mathrm{C}$ were $0.02853,0.03958,0.04865$, 0.05937 and 0.06943 , respectively. The $(D / L)_{\text {calib }}$ correlated with the hydrolysis times (Pearson correlation test; $p<0.05$, $r^{2}=1.000$ ) (Fig. 2), and yielded the following linear regression equation:

$(D / L)_{\text {calib }}=0.00145 \times$ hydrolysis time $(\mathrm{h})+0.0186$,

$\left(p<0.05, r^{2}=0.999\right)$.

The initial $(D / L)_{\text {calib }}$ in the lenses of whales was 0.0186 $(\mathrm{SD}=0.00112)$ calculated in Eq. (4).

Table 3 Relationship between the measurements and the real ratios of the standard solutions of aspartic acid

\begin{tabular}{llll}
\hline Asp $D / L$ & \multicolumn{3}{l}{ Measurements of Asp $D / L$} \\
\cline { 2 - 4 } & 1 & 2 & 3 \\
\hline 0.010 & 0.00797 & 0.00800 & 0.00810 \\
0.020 & 0.0163 & 0.0160 & 0.0158 \\
0.030 & 0.0254 & 0.0255 & 0.0255 \\
0.040 & 0.0339 & 0.0336 & 0.0340 \\
0.050 & 0.0427 & 0.0430 & 0.0428 \\
0.060 & 0.0518 & 0.0516 & 0.0513 \\
0.070 & 0.0602 & 0.0603 & 0.0603 \\
\hline
\end{tabular}




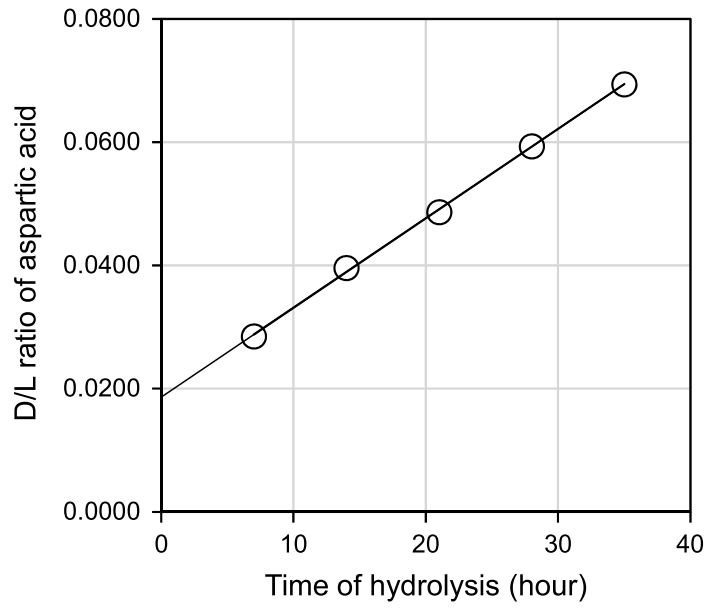

Fig. 2 Relationship between time of hydrolysis in sample preparation (h) and $D / L$ ratios of aspartic acid in lens of fetus of Antarctic minke whales

Therefore, to correct for the hydrolysis effect, $(D / L)_{\text {act }}$ 0.0186 was subtracted from the $(D / L)_{\text {calib }}$.

\section{Aspartic $D / L$ ratio at birth of whales}

Table 1 shows the $(D / L)_{\text {act }}$ in the lenses of fetuses of whales, and Fig. 3 shows the relationships between the $(D / L)_{\text {act }}$ and fetal ages (day). The $(D / L)_{\text {act }}$ correlated with fetal ages (Pearson correlation test $\left.p<0.05, r^{2}=0.394\right)$. The data yielded the following linear regression equation:

$(D / L)_{\text {act }}=0.0000122 \times$ fetal age $($ day $)+0.00941$,

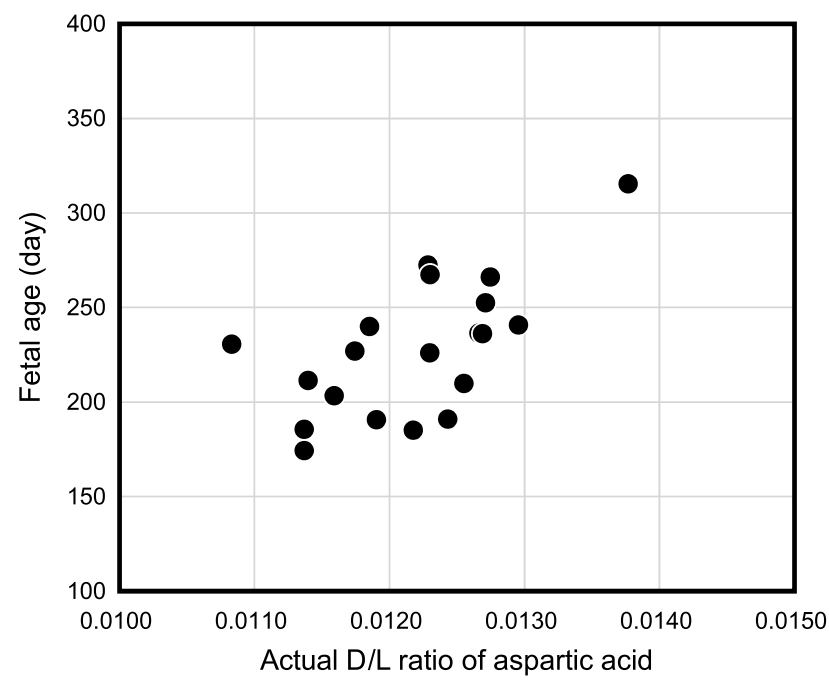

Fig. 3 Relationship between fetal ages (days) and ratios of aspartic enantiomers $(D / L)$ in fetuses of Antarctic minke whales $p<0.05, r^{2}=0.400$.

Thus, the $(D / L)_{0}$, which is the $(D / L)_{\text {act }}$ in lens of the Antarctic minke whale at birth, was estimated from this equation and 330 days of the gestational period as assumed for balaenopterid species by [19]. The estimate was $0.0134\left(\mathrm{SE}=3.78 \times 10^{-4}\right.$; 95\% confidential interval 0.0121-0.0147).

\section{Slope of the age estimation equation}

Table 2 shows the ratio of $(D / L)_{\text {act }}$ in the lenses of Antarctic minke whales corrected by the hydrolysis effect and the age index which is " $\log _{\mathrm{e}}\left\{\left[1+(D / L)_{\text {act }}\right] /\left[1-(D / L)_{\text {act }}\right]\right\}$ ". Figure 4 shows the relationships between the age indexes and earplug ages in Antarctic minke whales.

The single outlier at 40-years-old for which Cook's distance exceeded 2 was eliminated in the first regression analysis. Then, the two equations of age estimation are shown below [Eqs. (6) and (7)].

In Eq. (6) linear regression analysis were re-performed to determine $k_{\text {Asp }}$ in Eq. (2) substituting $(D / L)_{0}=0.0134$ using dataset of the $(D / L)_{\text {act }}$ and the earplug ages in the 17 whales (Fig. 4) as follows:

$$
\begin{aligned}
& \log _{\mathrm{e}}\left\{\left[1+(D / L)_{\text {act }}\right] /\left[1-(D / L)_{\text {act }}\right]\right\} \\
& \left.\quad=1.79 \times 10^{-3} \times \text { earplug age (year }\right)+0.0268, \\
& \therefore \quad p<0.001, \quad r^{2}=0.890, \quad k_{\text {Asp }}=8.94 \times 10^{-4}, \\
& \quad \mathrm{SE}\left(2 k_{\text {Asp }}\right)=1.52 \times 10^{-4} .
\end{aligned}
$$

In Eq. (7) linear regression analysis was performed to determine $k_{\text {Asp }}$ and $(D / L)_{0}$ in Eq. (2) using dataset of the

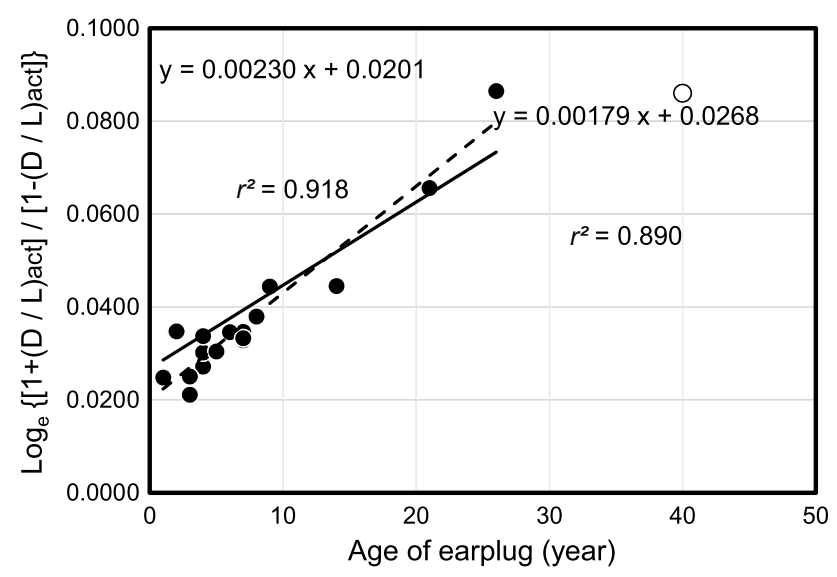

Fig. 4 Relationship between age indexes, $\log _{\mathrm{e}}\left[1+(D / L)_{\text {act }}\right] /$ $\left.\left[1-(D / L)_{\text {act }}\right]\right\}$, and ages of earplugs of Antarctic minke whales: open circle was excluded from simple linear regression analysis as an outlier, and a solid and broken line is calculated by Eqs. (5) and (6), respectively 
$(D / L)_{\text {act }}$ and the earplug ages in the 17 whales (Fig. 4) as follows:

$$
\begin{aligned}
& \log _{\mathrm{e}}\left\{\left[1+(D / L)_{\mathrm{act}}\right] /\left[1-(D / L)_{\mathrm{act}}\right]\right\} \\
& \quad=2.30 \times 10^{-3} \times \text { earplug age }(\text { year })+0.0201
\end{aligned}
$$

$\therefore \quad p<0.001, r^{2}=0.918, k_{\mathrm{Asp}}=1.15 \times 10^{-3}$,

$\operatorname{SE}\left(2 k_{\text {Asp }}\right)=1.71 \times 10^{-4}, \quad \operatorname{SE}($ intercept $)=1.72 \times 10^{-3}$.

Squared correlation coefficient of the Eq. (7) was higher than that of the Eq. (6), and the SE of $2 k_{\mathrm{Asp}}$ and intercept of the Eq. (7) were lower than those of the Eq. (6). Therefore Eq. (7) is more precise and accurate to estimate ages of whales than Eq. (6).

\section{Standard error of age estimated by AAR}

Ages estimated from Eq. (7) and $(D / L)_{\text {act }}$ in each whale, including their SEs and 95\% confidence intervals estimated by bootstrap simulation, are shown in Table 4 . Figure 5 shows the relationships between ages estimated from earplugs, and ages (including SEs and 95\% confidence intervals), estimated by the AAR. The range of SEs of the AARbased age estimates was 0.9 and 2.9 years, and they were within the $95 \%$ confidence interval, except for one case.

Table 4 Age estimated from earplugs and by the AAR in Antarctic minke whales

\begin{tabular}{lrrrl}
\hline Sample no. & $\begin{array}{l}\text { Age estimated } \\
\text { from earplugs }\end{array}$ & \multicolumn{3}{l}{ Age estimated by the AAR } \\
\cline { 3 - 5 } & & Age & SE & $95 \%$ CI \\
\hline 05/06-AM348 & 14 & 10.6 & 1.5 & 8.1 to 14.2 \\
05/06-AM349 & 21 & 19.8 & 2.2 & 16.1 to 25.0 \\
05/06-AM352 & 9 & 10.6 & 1.5 & 8.2 to 14.2 \\
05/06-AM361 & 26 & 28.9 & 2.9 & 24.2 to 35.7 \\
05/06-AM382 & 7 & 6.3 & 1.2 & 4.4 to 9.1 \\
05/06-AM386 & 8 & 7.8 & 1.3 & 5.6 to 10.8 \\
05/06-AM398 & 7 & 5.6 & 1.2 & 3.7 to 8.2 \\
05/06-AM488 & 4 & 3.1 & 1.0 & 1.4 to 5.3 \\
05/06-AM498 & 4 & 4.4 & 1.1 & 2.6 to 6.8 \\
05/06-AM517 & 3 & 0.5 & 0.8 & -0.9 to 2.3 \\
05/06-AM539 & 1 & 2.1 & 0.9 & 0.5 to 4.1 \\
05/06-AM565 & 2 & 6.4 & 1.2 & 4.4 to 9.1 \\
05/06-AM592 & 4 & 5.9 & 1.2 & 4.0 to 8.6 \\
05/06-AM603 & 6 & 6.3 & 1.2 & 4.3 to 9.1 \\
05/06-AM615 & 7 & 5.8 & 1.2 & 3.8 to 8.5 \\
05/06-AM630 & 5 & 4.5 & 1.1 & 2.8 to 7.0 \\
05/06-AM634 & 3 & 2.2 & 0.9 & 0.7 to 4.2 \\
\hline
\end{tabular}

${ }^{a}$ Ages estimated by the AAR were derived from Eq. (7), and their SEs and $95 \%$ CIs were estimated from bootstrap simulation

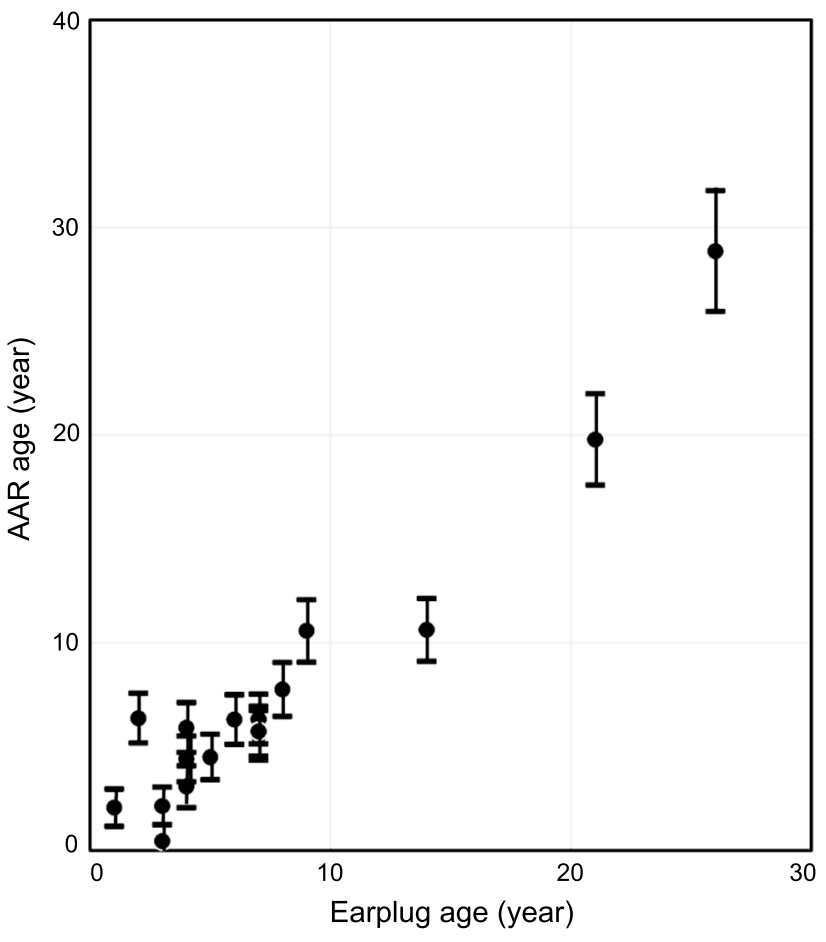

Fig. 5 Relationship between ages estimated by AAR and earplugs (averages and SEs estimated by bootstrap simulation) in Antarctic minke whales

\section{Discussion}

\section{Analytical linearity, precision and calibration of Asp $D / L$ analysis}

One of the important aspects of Asp $D / L$ analysis using the HPLC system is the validation concerning linearity, calibration and precision using the standard solutions of enantiomer mixtures of aspartic acid. In this study such evaluation was conducted, and the $(D / L)_{\text {meas }}$ showed excellent linearity in the range of 0.010 and 0.070 of $\mathrm{Asp} D / L$ in the standard solutions, and their precision $(\mathrm{CV})$ was under 0.0156 . The $(D / L)_{\text {meas }}$ was corrected to $(D / L)_{\text {act }}$ by Eq. (4).

\section{Effect of hydrolysis}

Another important aspect of this kind of study is the preparation process, especially hydrolysis, which could affect measurement values [20,21]. Different conditions of hydrolysis would make inter-laboratory comparisons of $k_{\text {Asp }}$ and $(D / L)_{0}$ difficult. The hydrolysis process for amino acid analysis induces racemization of amino acids, and the degree of racemization is affected by experimental conditions such as processing time, temperature, phase of acid, and additive agent [22]. Therefore, the degree of racemization must be determined by each laboratory in order to allow 
inter-laboratory comparison of the results, and this was done in the present study.

A decrease in the degree of racemization through the hydrolysis process contributes to improve the accuracy and precision of AAR age. This study adopted gas-phase hydrolysis, because the degree of racemization in gas-phase hydrolysis was lower than that in the liquid-phase [22] which is the common method for whale age estimation using AAR.

\section{Estimation of $(D / L)_{0}$ and $k_{\mathrm{Asp}}$}

$(D / L)_{0}$ determined directly from data of fetus or neonate contributes to age estimation by AAR with higher precision. Previous studies inferred the $(D / L)_{0}$ from a few data of juveniles [9] or data of whales in a wide range of age [12, $14]$. The present study attempted to determine $(D / L)_{0}$ based on a larger number of fetus's lens samples; however, the $(D / L)_{0}$ were not determined with a high degree of precision because of the hydrolysis effects.

It should be noted that only female samples were used as postnatal animals. This is potentially useful because ovulation rate in common minke whales is well documented, and it is possible to use the post-sexual maturity age as an independent validation of the age estimate [13]. On the other hand, the racemization rate of aspartic acid is only dependent of body temperature of whales, it is whereas unaffected by metabolism [13]. Then the method developed in this study should be also applicable to males.

A single outlier at a 40-years-old animal (earplug age) was eliminated based on Cook's score. Another reason for this was the possibility that the accelerated aspartic acid racemization rate originated from cataracts in lens of old mammals such as human [23] and rat [24]. The amount of changes of Asp $D / L$ in lens of younger animals was higher than older animals, because the Asp $D / L$ exponential decays in lens of mammals, suggesting that $k_{\mathrm{Asp}}$ is more precisely estimated for young animals. Therefore, the $k_{\text {Asp }}$ and the intercept for age estimation were calculated from 17 whales.

The $k_{\text {Asp }}$ in Antarctic minke whale was estimated to be $1.15 \times 10^{-3} /$ year $\left(\mathrm{SE}=1.71 \times 10^{-4} /\right.$ year $)$ from $\mathrm{Eq}$. (7). This value was similar to 1.16 in fin whales [12], $1.18 \times 10^{-3} /$ year in bowhead [9] and $1.10 \times 10^{-3}$ in common minke whale from the Atlantic [13], whereas it was slightly higher than $0.977 \times 10^{-3}$ in bowhead whales [14], suggesting the $k_{\text {Asp }}$ in the present study was appropriate.

\section{Standard error of the estimation of age from AAR}

In the present study the SEs of the age estimates from AAR were in the range of $0.8-2.9$ for age estimates in the range 0.5-29.2 years old. These SEs were lower than those of common minke whale from the Atlantic (SE 4.5-8.77 for 0-30 years old, [13]) and bowhead whales (SE 6-7 for -6 to 20 years old, [9]; and SE 2-5.5 for -6.5 to 29 years old [14]). Kitakado et al. [25] reported that the CV estimates for age estimation in relatively young Antarctic minke whales based on reading growth layers from earplugs among the five readers were in the range of $0.0041-0.0155$. In animals under the age of three, the AAR ages differed from the earplug ages. The reason for this is that the amount of Asp D yielded just after birth would be extremely lower than that produced by the hydrolysis process. This tendency had been reported in previous studies [9, 14].

This study was successful in developing the AAR technique for Antarctic minke whale with a few issues including possible bias due to cataract, requiring further consideration in the future. The application of this technique can complement the age estimation of this species based on earplug reading, especially for young animals with unreadable earplugs.

Acknowledgements We would like to thank the captains, crews and scientists involved in the 2005/2006 and 2007/2008 JARPA II surveys. We also thank Prof. Noriko Fujii, Research Reactor Institute, Kyoto University, for providing valuable comments on this paper. The JARPA II program was conducted with permission from the Fisheries Agency of the Government of Japan.

Open Access This article is distributed under the terms of the Creative Commons Attribution 4.0 International License (http://creativecommons.org/licenses/by/4.0/), which permits unrestricted use, distribution, and reproduction in any medium, provided you give appropriate credit to the original author(s) and the source, provide a link to the Creative Commons license, and indicate if changes were made.

\section{References}

1. Nishiwaki M (1950) Determination of the age of Antarctic blue and fin whales by the colour changes in crystalline lens. Sci Rep Whal Res Inst 4:115-161

2. Nishiwaki M (1951) On the periodic mark on the baleen plates as the sign of annual growth. Sci Rep Whal Res Inst 6:133-152

3. Zenitani R, Kato H (2010) The growth of baleen plates in Antarctic minke whales, with special reference to the V-Shape notch appearing at the outer edge of the plates. Nippon Suisan Gakkaishi 76:870-876 (in Japanese with English abstract)

4. Purves PE (1955) The wax plug in the external auditory meatus of the Mysticeti. Discov Rep 27:293-302

5. Lockyer C (1984) Age determination by means of the ear plug in baleen whales. Rep Int Whal Comm 34(683-84):692-696

6. Christensen I (1995) Interpretation of growth layers in periosteal zone of tympanic bulla from minke whales Balaenoptera acutorostrata. In: Brix AS et al (eds) Whales, seals fish and man. Elsevier Science, Amsterdam, pp 413-423

7. Lockyer C (1984) Review of baleen whale (Mysticeti) reproduction and implications for management. Rep Int Whal Comm 6:27-50

8. Maeda H, Kawamoto T, Kato H (2013) A study on the improvement of age estimation in common minke whales using the method of gelatinized extraction of earplug. NAMMCO Sci Publ. doi: $10.7557 / 3.260$ 
9. George JC, Bada J, Zeh H, Scott L, Brown SE, O’Hara T, Suydam R (1999) Age and growth estimates of bowhead whales (Balaena mysticetus) via aspartic acid racemization. Can J Zool 77:571-580

10. Bada JL, Brown SE, Masters PM (1980) Age determination of marine mammals based on aspartic acid racemization in the teeth and lens nucleus. Rep Int Whal Commn 3(special issue):113-118

11. Fujii N, Momose Y, Ishii N, Takita M, Akaboshi M, Kodama M (1999) The mechanisms of simultaneous stereoinversion, racemization, and isomerization at specific aspartyl residues of aged lens proteins. Mech Ageing Dev 107:347-358

12. Nerini MK (1983) Age determination of fin whales (Balaenoptera physalus) based upon aspartic acid racemisation in the lens nucleus. Rep Int Whal Comm 33:447-448

13. Olsen E, Sunde J (2002) Age determination of minke whales (Balaenoptera acutorostrata) using the aspartic acid racemization technique. Sarsia $87: 1-8$

14. Rosa C, Zeh J, George JC, Botta O, Zauscher M, Bada J, O'Hara TM (2013) Age estimates based on aspartic acid racemization for bowhead whales (Balaena mysticetus) harvested in 1998-2000 and the relationship between racemization rate and body temperature. Mar Mammal Sci 29(3):424-445

15. Hakamada T, Matsuoka K, Nishiwaki S, Kitakado T (2013) Abundance estimates and trends for Antarctic minke whales (Balaenoptera bonaerensis) in Antarctic Areas IV and V for the period 1989/90-2004/05. J Cetacean Res Manag 13(2):123-151

16. Kato H, Miyashita T (1991) Migration strategy of southern minke whales in relation to reproductive cycle estimated from foetal lengths. Rep Int Whal Comm 41:363-369

17. Fujii N, Ishibashi Y, Satoh K, Fujino M, Harada H (1994) Simultaneous racemization and isomerization at specific aspartic acid residues in $\alpha \mathrm{B}$-crystallin from the aged human lens. Biochim Biophys Acta 1204:157-163

18. R Core Team (2015) R: a language and environment for statistical computing. R Foundation for Statistical Computing, Vienna. https://R-project.org/

19. Kato H (1992) Body length, reproduction and stock separation of minke whales off northern Japan. Rep Int Whal Comm 42:443-453

20. Goodfriend GA, Meyer VR (1991) A comparative study of the kinetics of amino acid racemization/epimerization in fossil and modern mollusk shells. Geochim Cosmochim Acta 55:3355-3367

21. Garde E, Heide-Jørgensen MP, Hansen SH, Nachman G, Forchhammer MC (2007) Age-specific growth and remarkable longevity in narwhals (Monodon monoceros) from west Greenland as estimated by aspartic acid racemization. J Mammal 88(1):49-58

22. Fountoulakis M, Lahm H-W (1998) Hydrolysis and amino acid composition analysis of proteins. J Chromatogr A 826:109-134

23. Masters PM, Bada JL, Zigler JS Jr (1977) Aspartic acid racemization in the human lens during ageing and in cataract formation. Nature 268:71-73

24. Fujii N, Takeuchi N, Fujii N, Tezuka T, Kuge K, Tanaka T, Kamei A, Saito T (2004) Comparison of post-translational modifications of alpha A-crystallin from normal and hereditary cataract rats. Amino Acids 26:147-152

25. Kitakado T, Lockyer C, Punt AE (2013) A statistical model for quantifying age-reading errors and its application to the Antarctic minke whales. J Cetacean Res Manag 13(3):181-190 